\title{
Pseudotyped Lentiviral Vectors for Retrograde Gene Delivery into Target Brain Regions
}

\author{
Kenta Kobayashi ${ }^{1,2}$, Ken-ichi Inoue ${ }^{3}$, Soshi Tanabe ${ }^{3}$, Shigeki Kato ${ }^{4}$, Masahiko Takada ${ }^{3}$ \\ and Kazuto Kobayashi* *
}

${ }^{1}$ Section of Viral Vector Development, National Institute for Physiological Sciences, Okazaki, Japan, ${ }^{2}$ SOKENDAl (The Graduate University for Advanced Studies), Hayama, Japan, ${ }^{3}$ Systems Neuroscience Section, Department of Neuroscience, Primate Research Institute, Kyoto University, Inuyama, Japan, ${ }^{4}$ Department of Molecular Genetics, Institute of Biomedical

Sciences, Fukushima Medical University School of Medicine, Fukushima, Japan

OPEN ACCESS

Edited by:

Jackson Cioni Bittencourt,

University of São Paulo, Brazil

Reviewed by:

Yoland Smith,

Emory University, United States

Jonathan Nassi,

Inscopix, Inc., United States

Cátia M. Teixeira,

Nathan Kline Institute for Psychiatric

Research, United States

*Correspondence: Kazuto Kobayashi kazuto@fmu.ac.jp

Received: 02 May 2017 Accepted: 17 July 2017 Published: 02 August 2017

Citation:

Kobayashi K, Inoue K, Tanabe S, Kato S, Takada M and Kobayashi K

(2017) Pseudotyped Lentiviral Vectors for Retrograde Gene Delivery into Target Brain Regions.

Front. Neuroanat. 11:65. doi: 10.3389/fnana.2017.00065
Gene transfer through retrograde axonal transport of viral vectors offers a substantial advantage for analyzing roles of specific neuronal pathways or cell types forming complex neural networks. This genetic approach may also be useful in gene therapy trials by enabling delivery of transgenes into a target brain region distant from the injection site of the vectors. Pseudotyping of a lentiviral vector based on human immunodeficiency virus type 1 (HIV-1) with various fusion envelope glycoproteins composed of different combinations of rabies virus glycoprotein (RV-G) and vesicular stomatitis virus glycoprotein (VSV-G) enhances the efficiency of retrograde gene transfer in both rodent and nonhuman primate brains. The most recently developed lentiviral vector is a pseudotype with fusion glycoprotein type $E$ (FuG-E), which demonstrates highly efficient retrograde gene transfer in the brain. The FuG-E-pseudotyped vector permits powerful experimental strategies for more precisely investigating the mechanisms underlying various brain functions. It also contributes to the development of new gene therapy approaches for neurodegenerative disorders, such as Parkinson's disease, by delivering genes required for survival and protection into specific neuronal populations. In this review article, we report the properties of the FuG-E-pseudotyped vector, and we describe the application of the vector to neural circuit analysis and the potential use of the FuG-E vector in gene therapy for Parkinson's disease. Keywords: lentiviral vector, fusion envelope glycoprotein, retrograde gene transfer, specific neuronal pathway,
gene therapy, Parkinson's disease

\section{INTRODUCTION}

To understand the mechanisms underlying brain functions controlled through complex neural networks, an analysis of the functions of specific neuronal pathways and cell types forming these complex networks is necessary. Recently, we developed a novel lentiviral vector-mediated retrograde gene transfer system that enables analysis of a specific neuronal pathway in the central nervous system (Kato et al., 2013; Kobayashi et al., 2016a, 2017). This system may also be applicable to gene therapy approaches for neurodegenerative disorders by enabling the introduction of transgenes that are involved in neuronal protection and survival into target brain regions.

Retrograde axonal transport of viral vectors offers a substantial advantage for the delivery of a transgene into neuronal populations innervating the injection site of viral vectors (Baumgartner and Shine, 1998; Perrelet et al., 2000; Azzouz et al., 2004; Zheng et al., 2005; Barkats et al., 2006). 
Among various kinds of lentiviral vectors, the human immunodeficiency virus type 1 (HIV-1)-based lentiviral vector has been the most commonly used for experimental studies. The HIV-1-based lentiviral vector is a valuable tool for gene therapy trials because it is able to transduce nondividing cells as well as dividing cells, in contrast to other retroviral vectors (Thomas et al., 2003; Kafri, 2004; Wong et al., 2006). The HIV-1-based lentiviral vector possesses a large packaging capacity (8-10 kb; Thomas et al., 2003), and its viral particles are integrated into host genomes after infection (Butler et al., 2002). This vector can be changed by genetically manipulating envelope glycoproteins essential for the vector transduction (reviewed by Cronin et al., 2005; Kobayashi et al., 2017). A conventional type of the HIV-1-based lentiviral vector pseudotyped with vesicular stomatitis virus glycoprotein (VSV-G) has a low efficiency for retrograde gene transfer, which can be improved by pseudotyping with selective variants of rabies virus glycoprotein (RV-G; Mentis et al., 2006; Kato et al., 2007; Federici et al., 2009). To enhance the efficiency of retrograde gene delivery, we previously developed a novel lentiviral vector capable of highly efficient retrograde gene transfer (HiRet) by pseudotyping with fusion glycoprotein type B (FuG-B), which is composed of the extracellular/transmembrane domains of RV-G and the intracellular domain of VSV-G (Kato et al., 2011a,b). Subsequently, we developed another type of lentiviral vector for neuron-specific retrograde gene transfer (NeuRet) with fusion glycoprotein type $\mathrm{C}(\mathrm{FuG}-\mathrm{C})$, which contains the N-terminal region of the extracellular domain (439 amino acids) of RV-G and the membrane-proximal region of the extracellular domain (16 amino acids) and transmembrane/cytoplasmic domains of VSV-G (Kato et al., 2011c). Figure 1 shows the structure of the glycoprotein. The HiRet and NeuRet vectors exhibit HiRet into various neuronal populations in both mouse and monkey brains (Kato et al., 2011a,c). However, these vectors possess a clear difference in gene transduction property around the injection site; specifically, the HiRet vector efficiently transduces dividing glial and neural stem/progenitor cells, whereas the NeuRet vector scarcely transduces these dividing cells (Kato et al., 2011c). This unique character of the NeuRet vector critically protects against the risk of tumorigenesis caused by altered expression of cellular oncogenes surrounding the insertion site (Li et al., 2002; Hacein-Bey-Abina et al., 2003; Themis et al., 2005; Beard et al., 2007; Marumoto et al., 2009).

Recently, we further developed a novel type of the NeuRet vector with fusion glycoprotein type $\mathrm{E}$ (FuG-E) during testing of various glycoproteins, with a shift in the junction between RV-G and VSV-G sequences (Kato et al., 2014). The FuG-E-pseudotyped NeuRet vector displays greater efficiency of retrograde gene transfer in both rodent and nonhuman primate brains compared to the previously developed NeuRet vector. In this review article, we summarize the properties of the FuG-E-pseudotyped NeuRet vector. We also report the application of the FuG-E vector for analyzing the neural circuit mechanism, and we describe the potential use of this vector in gene therapy for neurodegenerative diseases, such as Parkinson's disease.

\section{DEVELOPMENT OF THE NEURET VECTOR PSEUDOTYPED WITH FUG-E}

Our previous studies suggest that pseudotyping of lentiviral vectors with different types of fusion glycoproteins influences the efficiency of retrograde gene transfer and the transduction property of cells around the injection site (for review see Kobayashi et al., 2017). As observed with FuG-C, fusion in the membrane-proximal region of viral envelope glycoproteins improves the efficiency of retrograde gene transfer and suppresses gene transduction into dividing cells around the injection site (Kato et al., 2011c). However, the position of the junction between RV-G and VSV-G segments in fusion glycoproteins that confers the most efficient gene transfer has been unclear. To optimize the junction of these two glycoproteins for efficient retrograde gene transfer, we produced various types of chimeric glycoproteins, in which the junction between the RV-G and VSV-G segments diverged in their membrane-proximal region, and we tested the in vivo gene transfer activity of the pseudotyped vectors (Kato et al., 2014). First, we screened the pseudotyped vectors based on the efficiency of gene delivery into thalamic neurons after intrastriatal injection in mice. We found that the vector pseudotyped with FuG-E, comprising the $\mathrm{N}$-terminal region of the extracellular domain (440 amino acids) of RV-G and the membrane-proximal region of the extracellular domain (15 amino acids) and transmembrane/cytoplasmic domains of VSV-G (see Figure $\mathbf{1}$ for the structure of glycoprotein), displayed the most efficient retrograde gene transfer into thalamostriatal neurons (i.e., a 1.2-fold greater transduction compared with the original FuG-C vector, based on data from Kato et al., 2014). The FuG-E vector also showed a high level of retrograde gene delivery into corticostriatal neurons in different cortical areas of the mouse brain, with a similar extent of gene transduction into thalamostriatal neurons. In addition, this vector pseudotype retained the property of neuron-specific gene transduction around the injection site. The typical expression pattern of the FuG-E vector through retrograde gene transfer in the mouse brain is shown in Figure 2.

\section{GENE DELIVERY OF FUG-E-PSEUDOTYPED VECTOR INTO NONHUMAN PRIMATE BRAIN}

The gene transfer pattern of the FuG-E-pseudotyped vector was investigated in the nonhuman primate brain (Tanabe et al., 2017). The FuG-E pseudotype was injected into the striatum of macaque monkeys, and the efficiency of retrograde gene transfer was compared to that of the parental FuG-C-pseudotyped vector. The FuG-E vector exhibited greater efficiency of retrograde gene transfer into various neuronal populations in subcortical regions innervating the striatum than the FuG-C vector; specifically, 1.2-, 2.0- and 1.4-fold elevation of transfer efficiency into the substantia nigra pars compacta, centromedian-parafascicular nuclear complex of the thalamus, and centrolateral nucleus of the thalamus, respectively (data from Tanabe et al., 2017). 


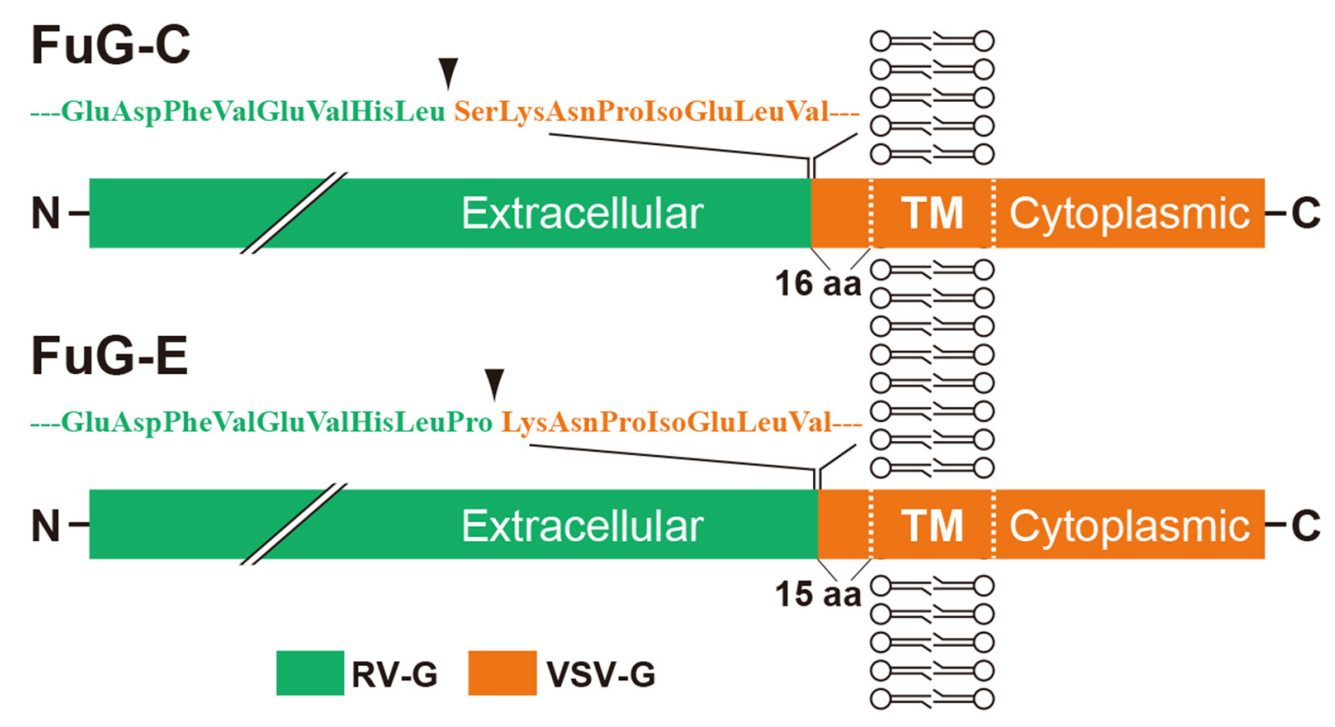

FIGURE 1 | Schematic representations of the structures of fusion glycoprotein types C (FuG-C) and E (FuG-E) used for the NeuRet vector. The extracellular, transmembrane (TM), and cytoplasmic domains are indicated. The amino acid sequences in the membrane proximal region of viral glycoprotein are indicated. Arrowheads show the position of junction between the rabies virus glycoprotein (RV-G) and vesicular stomatitis virus glycoprotein (VSV-G) segments.

In cortical areas, the gene transfer efficiency of the FuG-E vector in the hemisphere ipsilateral to the vector-injected side was 2.2-, 2.1-, 2.1- and 1.7-fold higher in the primary motor area, supplementary motor area, Brodmann's area $8 \mathrm{~b}$ and Brodmann's area 46d, respectively as compared with that of the FuG-C vector, and the efficiency of the FuG-E vector in the contralateral hemisphere was increased to 5.8-, 4.1-, 8.7- and 5.9-fold of the value of the FuG-C vector in the respective four areas (data from Tanabe et al., 2017). Moreover, the FuG-E vector maintained the property of neuronspecific gene transduction around the injection site. The representative gene expression pattern of the FuG-E vector via retrograde gene transfer in the monkey brain is demonstrated in Figure 3.

These analyses highlight that the FuG-E-pseudotyped vector achieves retrograde gene delivery with greater efficiency compared with the NeuRet vector pseudotyped with FuG-C, suggesting the important role of the sequences of the membraneproximal regions of viral envelope glycoproteins in retrograde gene delivery. This type of vector therefore provides a powerful experimental strategy to investigate the mechanisms underlying various neural functions more precisely, and it offers a promising genetic tool for gene therapy trials for neurological and neurodegenerative disorders.

\section{OTHER VIRAL VECTORS FOR RETROGRADE GENE TRANSFER}

Rabies virus (RV) is well known to spread transsynaptically in the retrograde direction in the central nervous system (Ugolini, 2008). A recombinant glycoprotein-deleted RV (RV $\Delta \mathrm{G})$ vector has widely been used for network-tracing studies (Callaway, 2008; Callaway and Luo, 2015). The RV $\Delta \mathrm{G}$ vector pseudotyped with the envelope protein of subgroup A avian sarcoma and leukosis virus (EnvA) can specifically infect neurons that have been genetically targeted for expression of the EnvA receptor (TVA). The trans-complementation of the RV $\Delta \mathrm{G}$ vector with $\mathrm{RV}-\mathrm{G}$ in neurons expressing TVA allows the vector to move monosynaptically to neuronal populations projecting to the TVA-expressing neurons (Wickersham et al., 2007; Miyamichi et al., 2011; Beier et al., 2015; Schwarz et al., 2015). This system is commonly used to identify the direct monosynaptic input to genetically defined neurons. Moreover, a pseudorabies virus (PRV) vector (Pomeranz et al., 2005; Braz et al., 2009; Ohara et al., 2009; Oyibo et al., 2014), a herpes simplex virus type 1 vector (Zemanick et al., 1991; LaVail et al., 1997; Fenno et al., 2014; Gremel et al., 2016) and a canine adenovirus serotype 2 vector (Bru et al., 2010; Senn et al., 2014) can also be transported retrogradely through axons. Among the viral vectors already mentioned, the RV and PRV vectors have often been used for short-term experimental studies such as retrograde neuron labeling. These vectors, like the lentiviral vector, can be handled under biosafety level 2 conditions. However, neither the RV nor the PRV vector are necessarily suitable for prolonged physiological studies because of cytotoxicity; the lentiviral vector does not share this characteristic. Properly detoxified viral vectors would be useful for various physiological applications over a long period of time.

Some serotypes of AAV vectors transfer foreign genes in a retrograde fashion in the central nervous system (Masamizu et al., 2011; Aschauer et al., 2013; Löw et al., 2013; Salegio et al., 2013; San Sebastian et al., 2013). In addition, a new AAV variant vector, termed rAAV2-retro vector, has recently been shown to robustly induce transgene expression in the retrograde direction (Tervo et al., 2016). In the future, stringent comparison 


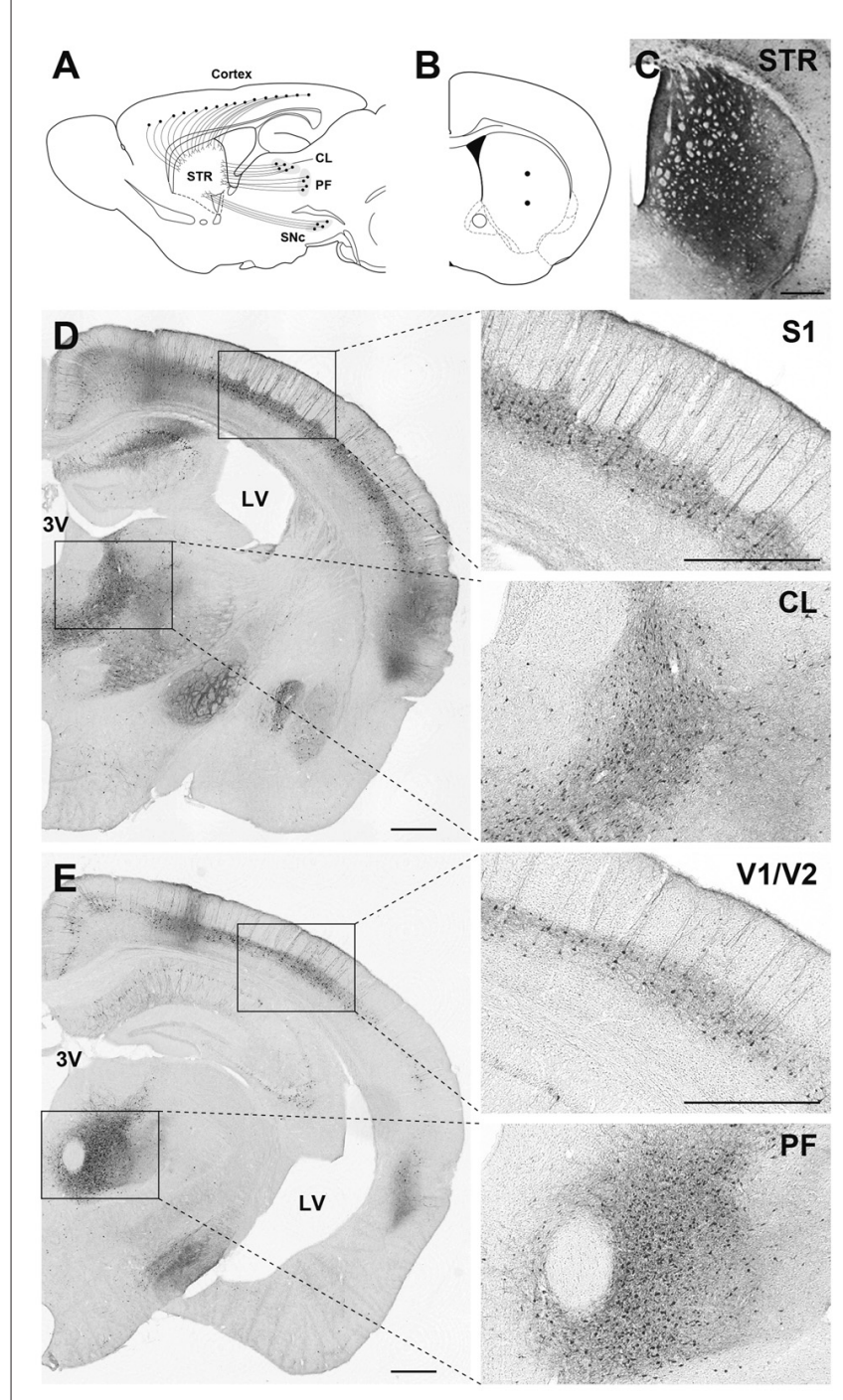

FIGURE 2 | Gene transfer pattern by fusion glycoprotein type E (FuG-E) vector through retrograde gene delivery in the mouse brain. (A) Schematic diagram of the projections that innervate the striatum (STR) in mice. CL, central lateral nucleus of the thalamus; PF, parafascicular nucleus of the thalamus; SNc, substantia nigra pars compacta. (B) Coordinates for intrastriatal injections. Dots indicate the injection sites. (C-E) Immunohistochemical detection of transgene expression. The FuG-E-pseudotyped vector encoding GFP transgene $\left(3.6 \times 10^{12}\right.$ genome copies $/ \mathrm{ml}, 0.75 \mu \mathrm{l} / \mathrm{site}$ for two sites) was injected into the STR in mice, and brain sections through the STR (C), CL (D) and PF (E) were used for immunohistochemical staining with anti-GFP antibody. Many immunopositive cells were detected in various neuronal populations in cortical areas including the primary somatosensory cortex (S1), primary and secondary visual cortices (V1N2), and the intralaminar thalamic regions (CL, PF) that innervate the STR. Right images are magnified views of the squares in the left image $(\mathbf{A})$ or $(\mathbf{B})$ $3 \mathrm{~V}$, third ventricle; LV, lateral ventricle. Scale bar: $500 \mu \mathrm{m}$.

of the efficiency of retrograde gene transfer of the FuG-E vector and these AAV vectors will be necessary in various neuronal pathways of diverse animal models. A major drawback of the $\mathrm{AAV}$ vector is that the packaging size of the transgene is limited, and large genes are therefore not currently suitable for use. The lentiviral vector can convey a larger transgene $(8-10 \mathrm{~kb})$ than the
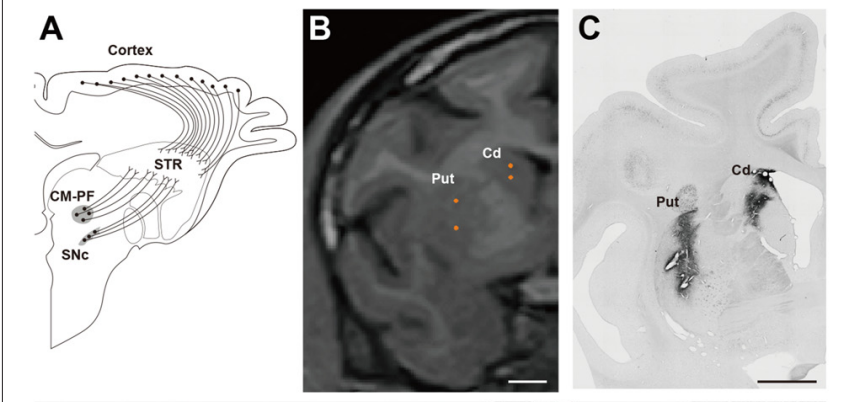

D

M1



FIGURE 3 | Gene transfer pattern by FuG-E vector via retrograde gene delivery in the monkey brain. (A) Schematic diagram of the projections that innervate the striatum (STR) in macaque monkeys. CM-PF, centromedian -parafascicular complex of the thalamus; SNc, substantia nigra pars compacta. (B) Coordinates for intrastriatal injections. Representative injection sites in the caudate nucleus (Cd) and putamen (Put) are shown in a magnetic resonance image. (C,D) Immunohistochemical detection of transgene expression. The FuG-E-pseudotyped vector encoding GFP transgene $\left(7.0 \times 10^{10}\right.$ genome copies $/ \mathrm{ml}, 3-5 \mu \mathrm{l} / \mathrm{site} \times 16$ sites) was injected into the $\mathrm{Cd}$ and Put in a macaque monkey and brain sections through the STR (C) and other brain regions (D) were immunostained with anti-GFP antibody. A number of immunopositive cells were detected in various neuronal populations in cortical areas including the primary motor cortex (M1), thalamic (CM), and nigral (SNc) regions innervating the STR. Right images are magnified views of the squares in the left image. $\mathrm{LV}$, lateral ventricle. Scale bar: $2 \mathrm{~mm}$.

AAV vector (5 kb; Thomas et al., 2003), so the FuG-E vector enables use of more genes of interest than the AAV vector. If the AAV vector could be modified to carry a larger transgene, it would provide a more powerful experimental tool for analysis of brain functions. Also, the AAV vector can be handled under biosafety level 1 conditions, while the lentiviral vector is a biosafety level 2 organism; consequently, the AAV vector is more tractable than the lentiviral vector. In addition, AAV vector particles are physiochemically more stable and can be preserved for a far longer period than lentiviral vector particles. A more durable lentiviral vector with a high efficiency of retrograde 
gene transfer would offer an extremely appealing experimental tool.

\section{APPLICATION OF FUG-E VECTOR TO NEURAL CIRCUIT ANALYSIS}

The FuG-E-pseudotyped vector has provided a useful gene engineering tool for experimental studies of neural circuit functions (for review see Kobayashi et al., 2017). For instance, the neural circuit mechanism underlying motor function recovery following stroke was investigated by selectively and reversibly blocking the specific neuronal pathway (Ishida et al., 2016). When synaptic transmission in the neuronal pathway projecting from the ipsilesional motor cortex to the ipsilesional red nucleus was reversibly blocked, rehabilitated rats displayed a remarkable decrease in motor performance, indicating an essential role of the ipsilateral cortico-red nucleus pathway in motor function recovery through rehabilitation (Ishida et al., 2016). The role of propriospinal neuron-mediated neuronal pathway in the recovery of hand dexterity after corticospinal tract lesions was examined by the same synaptic blockade procedure (Tohyama et al., 2017). In monkeys, recovery of dexterous hand movements after corticospinal tract lesions was perturbed by reversibly blocking the synaptic transmission from propriospinal neurons to spinal motor neurons, showing an important role of the propriospinal neuron-spinal motor neuron pathway in promoting the recovery of hand dexterity after the lesion. When the activity of dopaminergic pathway from the ventral tegmental area to the nucleus accumbens was specifically suppressed by a chemogenetic approach in mice under a neuropathic pain-like state, exercise-induced hypoalgesia was markedly impaired (Wakaizumi et al., 2016). These results indicate that the ventral tegmental area-nucleus accumbens pathway is involved in the anti-nociception effect caused by exercise under a neuropathic pain-like state. In a recent report, we investigated the role of a small GTPase Rho signaling pathway mediated by Rho-kinase, one of the major target molecules of Rho, in corticostriatal neuron survival (Kobayashi et al., 2016b). Conditional blockade of the Rho/Rho-kinase signaling pathway in mouse corticostriatal neurons caused a marked decrease in the number of these neurons, which was attributed to enhanced apoptosis (Kobayashi et al., 2016b). These data show that the Rho/Rho-kinase signaling pathway is essential for the survival of corticostriatal neurons. In addition, the FuG-E vector is certainly applicable to other experimental strategies, such as selective pathway targeting (Kato et al., 2011b; Inoue et al., 2012) and optogenetic (Matsuda et al., 2017) techniques.

\section{POTENTIAL USE OF FUG-E VECTOR IN GENE THERAPY TRIALS FOR PARKINSON'S DISEASE}

Parkinson's disease is a neurodegenerative disorder characterized by progressive loss of nigrostriatal dopaminergic neurons; the loss of these neurons induces motor dysfunctions (Fahn, 2003; Obeso et al., 2010). Various gene therapy trials targeting dopaminergic neurons have been carried out using a rodent or a nonhuman primate model of Parkinson's disease (Kim et al., 2012; Redmond et al., 2013; Ren et al., 2013; Oh et al., 2015). However, gene transfer specifically into nigrostriatal dopaminergic neurons has not yet been achieved. Gene transfer into specific neuronal populations enables assessment of the clinical effects of the transgene without the effect of nonspecific transgene actions in other cell populations. The FuG-E vector achieves a higher efficiency of retrograde gene delivery compared with the previously developed NeuRet vector, and it permits neuron-specific gene transduction around the injection site in the brain (Kato et al., 2014). Interestingly, retrograde gene transfer of the FuG-E vector into mouse nigrostriatal dopaminergic neurons is less efficient, whereas the FuG-E vector displays remarkably high transduction efficiency into the dopaminergic neurons in monkeys (Tanabe et al., 2017). In the near future, our newly developed FuG-E vector system with these attractive characteristics may serve as a powerful genetic tool in gene therapy trials for Parkinson's disease.

\section{CONCLUSION}

Gene transduction via viral vectors offers great advantages in genetic manipulation of neural circuit functions in diverse animal models, including rodents and nonhuman primates. We have developed novel types of lentiviral vectors, the HiRet and NeuRet vectors, which display HiRet in the central nervous system. These viral vectors enable analysis of the roles of specific neuronal pathways or signaling molecules with critical functions in complex neural circuits. Viral vector-mediated retrograde gene delivery is a particularly important genetic technology in nonhuman primates because conventional transgenic approaches generally used for mice are hardly applicable to monkeys. Notably, the NeuRet vector possesses a unique characteristic in that it scarcely transduces dividing glial and neural stem/progenitor cells around the injection site. This property of the NeuRet vector is essential for genetic treatment of neurodegenerative diseases because viral vector integration into dividing cells may increase the risk of tumorigenesis in the brain. The NeuRet vector permits reducing the risk of tumorigenesis by suppressing gene delivery into glial and neural stem/progenitor cells. The NeuRet vector exhibits efficient retrograde gene transfer into the nigrostriatal pathway in primates, and the FuG-E vector has remarkably higher gene transfer efficiency in this pathway than the FuG-C vector. The FuG-E vector possessing these advantageous characteristics could contribute to the development of novel primate models for Parkinson's disease. Furthermore, the FuG-E vector may provide promising approaches to gene therapy for Parkinson's disease by delivering genes required for neuronal survival and protection into nigrostriatal dopaminergic neurons.

\section{ETHICS STATEMENT}

All experiments were performed in accordance with the guidelines of the National Institutes of Health, and were 
approved by the Animal Research Committee of Fukushima Medical University for rodents and the Animal Welfare and Animal Care Committee of the Primate Research Institute, Kyoto University for monkeys. We made all efforts to minimize the number of animals used and their suffering.

\section{AUTHOR CONTRIBUTIONS}

KeK wrote the present manuscript; KI, ST and SK designed figures; MT and KaK critically read and edited the manuscript.

\section{REFERENCES}

Aschauer, D. F., Kreuz, S., and Rumpel, S. (2013). Analysis of transduction efficiency, tropism and axonal transport of AAV serotypes 1, 2, 5, 6, 8 and 9 in the mouse brain. PLoS One 8:e76310. doi: 10.1371/journal.pone.0076310

Azzouz, M., Ralph, G. S., Storkebaum, E., Walmsley, L. E., Mitrophanous, K. A., Kingsman, S. M., et al. (2004). VEGF delivery with retrogradely transported lentivector prolongs survival in a mouse ALS model. Nature 429, 413-417. doi: 10.1038/nature02544

Barkats, M., Horellou, P., Colin, P., Millecamps, S., Faucon-Biguet, N., and Mallet, J. (2006). 1-Methyl-4-phenylpyridinium neurotoxicity is attenuated by adenoviral gene transfer ofhuman $\mathrm{Cu} / \mathrm{Zn}$ superoxide dismutase. J. Neurosci. Res. 83, 233-242. doi: 10.1002/jnr.20696

Baumgartner, B. J., and Shine, H. D. (1998). Neuroprotection of spinal motoneurons following targeted transduction with an adenoviral vector carrying the gene for glial cell line-derived neurotrophic factor. Exp. Neurol. 153, 102-112. doi: 10.1006/exnr.1998.6878

Beard, B. C., Dickerson, D., Beebe, K., Gooch, C., Fletcher, J., Okbinoglu, T., et al. (2007). Comparison of HIV-derived lentiviral and MLV-based gammaretroviral vector integration sites in primate repopulating cells. Mol. Ther. 15, 1356-1365. doi: 10.1038/sj.mt.6300159

Beier, K. T., Steinberg, E. E., DeLoach, K. E., Xie, S., Miyamichi, K., Schwarz, L., et al. (2015). Circuit architecture of VTA dopamine neurons revealed by systematic input-output mapping. Cell 162, 622-634. doi: 10.1016/j.cell.2015. 07.015

Braz, J. M., Enquist, L. W., and Basbaum, A. I. (2009). Inputs to serotonergic neurons revealed by conditional viral transneuronal tracing. J. Comp. Neurol. 514, 145-160. doi: 10.1002/cne.22003

Bru, T., Salinas, S., and Kremer, E. J. (2010). An update on canine adenovirus type 2 and its vectors. Viruses 2, 2134-2153. doi: 10.3390/v2092134

Butler, S. L., Johnson, E. P., and Bushman, F. D. (2002). Human immunodeficiency virus cDNA metabolism: notable stability of two-long terminal repeat circles. J. Virol. 76, 3739-3747. doi: 10.1128/jvi.76.8.3739-3747.2002

Callaway, E. M. (2008). Transneuronal circuit tracing with neurotropic viruses. Curr. Opin. Neurobiol. 18, 617-623. doi: 10.1016/j.conb.2009.03.007

Callaway, E. M., and Luo, L. (2015). Monosynaptic circuit tracing with glycoprotein-deleted rabies viruses. J. Neurosci. 35, 8979-8985. doi: 10.1523/JNEUROSCI.0409-15.2015

Cronin, J., Zhang, X.-Y., and Reiser, J. (2005). Altering the tropism of lentiviral vectors through pseudotyping. Curr. Gene Ther. 5, 387-398. doi: $10.2174 / 1566523054546224$

Fahn, S. (2003). Description of Parkinson's disease as a clinical syndrome. Ann. N Y Acad. Sci. 991, 1-14. doi: 10.1111/j.1749-6632.2003.tb07458.x

Federici, T., Kutner, R., Zhang, X-Y., Kuroda, H., Tordo, N., Boulis, N. M., et al. (2009). Comparative analysis of HIV-1-based lentiviral vectors bearing lyssavirus glycoproteins for neuronal gene transfer. Genet. Vaccines Ther. 7:1. doi: 10.1186/1479-0556-7-1

Fenno, L. E., Mattis, J., Ramakrishnan, C., Hyun, M., Lee, S. Y., He, M., et al. (2014). Targeting cells with single vectors using multiple-feature Boolean logic. Nat. Methods 11, 763-772. doi: 10.1038/nmeth.2996

Gremel, C. M., Chancey, J. H., Atwood, B. K., Luo, G., Neve, R., Ramakrishnan, C., et al. (2016). Endocannabinoid modulation of orbitostriatal circuits gates habit formation. Neuron 90, 1312-1324. doi: 10.1016/j.neuron.2016. 04.043

\section{ACKNOWLEDGMENTS}

This work was supported by a grant-in-aid for Scientific Research on Innovative Areas "Adaptive Circuit Shift” (26112002 to KaK and $17 \mathrm{H} 05565$ to KI) from the Ministry of Education, Science, Sports and Culture of Japan. We thank Dr. A. Nambu and T. Isa for valuable discussions; Dr. Ira Pastan for providing the recombinant immunotoxin; and St. Jude Children's Research Hospital (Dr. A. Nienhuis) and George Washington University for providing the HIV-1-based vector system.

Hacein-Bey-Abina, S., Von Kalle, C., Schmidt, M., McCormack, M. P., Wulffraat, N., Leboulch, P., et al. (2003). LMO2-associated clonal T cell proliferation in two patients after gene therapy for SCID-X1. Science 302, 415-419. doi: 10.1126/science.1088547

Inoue, K., Koketsu, D., Kato, S., Kobayashi, K., Nambu, A., and Takada, M. (2012). Immunotoxin-mediated tract targeting in the primate brain: selective elimination of the cortico-subthalamic "hyperdirect" pathway. PLoS One 7:e39149. doi: 10.1371/journal.pone.0 039149

Ishida, A., Isa, K., Umeda, T., Kobayashi, K., Kobayashi, K., Hida, H., et al. (2016). Causal link between the cortico-rubral pathway and functional recovery through forced impaired limb use in rats with stroke. J. Neurosci. 36, 455-467. doi: 10.1523/JNEUROSCI.2399-15.2016

Kafri, T. (2004). Gene delivery by lentivirus vectors an overview. Methods Mol. Biol. 246, 367-390. doi: 10.1385/1-59259-650-9:367

Kato, S., Inoue, K., Kobayashi, K., Yasoshima, Y., Miyachi, S., Inoue, S., et al. (2007). Efficient gene transfer via retrograde transport in rodent and primate brains using a human immunodeficiency virus type 1-based vector pseudotyped with rabies virus glycoprotein. Hum. Gene Ther. 18, 1141-1151. doi: 10.1089/hum.2007.082

Kato, S., Kobayashi, K., Inoue, K., Kuramochi, M., Okada, T., Yaginuma, H., et al. (2011a). A lentiviral strategy for highly efficient retrograde gene transfer by pseudotyping with fusion envelope glycoprotein. Hum. Gene Ther. 22, 197-206. doi: 10.1089/hum.2009.179

Kato, S., Kuramochi, M., Kobayashi, K., Fukabori, R., Okada, K., Uchigashima, M., et al. (2011b). Selective neural pathway targeting reveals key roles of thalamostriatal projection in the control of visual discrimination. J. Neurosci. 31, 17169-17179. doi: 10.1523/JNEUROSCI.400511.2011

Kato, S., Kuramochi, M., Takasumi, K., Kobayashi, K., Inoue, K., Takahara, D., et al. (2011c). Neuron-specific gene transfer through retrograde transport of lentiviral vector pseudotyped with a novel type of fusion envelope glycoprotein. Hum. Gene Ther. 22, 1511-1523. doi: 10.1089/hum.20 11.111

Kato, S., Kobayashi, K., and Kobayashi, K. (2013). Dissecting circuit mechanisms by genetic manipulation of specific neural pathways. Rev. Neurosci. 24, 1-8. doi: 10.1515/revneuro-2012-0043

Kato, S., Kobayashi, K., and Kobayashi, K. (2014). Improved transduction efficiency of a lentiviral vector for neuron-specific retrograde gene transfer by optimizing the junction of fusion envelope glycoprotein. J. Neurosci. Methods 227, 151-158. doi: 10.1016/j.jneumeth.2014. 02.015

Kim, S. R., Kareva, T., Yarygina, O., Kholodilov, N., and Burke, R. E. (2012). AAV transduction of dopamine neurons with constitutively active Rheb protects from neurodegeneration and mediates axon regrowth. Mol. Ther. 20, 275-286. doi: $10.1038 / \mathrm{mt} .2011 .213$

Kobayashi, K., Kato, S., Inoue, K., Takada, M., and Kobayashi, K. (2016a). Altering entry site preference of lentiviral vectors into neuronal cells by pseudotyping with envelope glycoproteins. Methods Mol. Biol. 1382, 175-186. doi: 10.1007/978-1-4939-3271-9_12

Kobayashi, K., Sano, H., Kato, S., Kuroda, K., Nakamuta, S., Isa, T., et al. (2016b). Survival of corticostriatal neurons by Rho/Rho-kinase signaling pathway. Neurosci. Lett. 630, 45-52. doi: 10.1016/j.neulet.2016. 07.020 
Kobayashi, K., Kato, S., and Kobayashi, K. (2017). Genetic manipulation of specific neural circuits by use of a viral vector system. J. Neural Transm. doi: 10.1007/s00702-016-1674-7 [Epub ahead of print].

LaVail, J. H., Topp, K. S., Giblin, P. A., and Garner, J. A. (1997). Factors that contribute to the transneuronal spread of herpes simplex virus. J. Neurosci. Res. 49, 485-496. doi: 10.1002/(sici)1097-4547(19970815)49:4<485::aid-jnr9>3.3. co;2-n

Li, Z., Düllmann, J., Schiedlmeier, B., Schmidt, M., von Kalle, C., Meyer, J., et al. (2002). Murine leukemia induced by retroviral gene marking. Science 296:497. doi: $10.1126 /$ science. 1068893

Löw, K., Aebischer, P., and Schneider, B. L. (2013). Direct and retrograde transduction of nigral neurons with AAV6, 8, and 9 and intraneuronal persistence of viral particles. Hum. Gene Ther. 24, 613-629. doi: 10.1089/hum. 2012.174

Marumoto, T., Tashiro, A., Friedmann-Morvinski, D., Scadeng, M., Soda, Y., Gage, F. H., et al. (2009). Development of a novel mouse glioma model using lentiviral vectors. Nat. Med. 15, 110-116. doi: 10.1038/nm.1863

Masamizu, Y., Okada, T., Kawasaki, K., Ishibashi, H., Yuasa, S., Takeda, S., et al. (2011). Local and retrograde gene transfer into primate neuronal pathways via adeno-associated virus serotype 8 and 9. Neuroscience 193, 249-258. doi: 10.1016/j.neuroscience.2011.06.080

Matsuda, T., Hiyama, T. Y., Niimura, F., Matsusaka, T., Fukamizu, A., Kobayashi, K., et al. (2017). Distinct neural mechanisms for the control of thirst and salt appetite in the subfornical organ. Nat. Neurosci. 20, 230-241. doi: $10.1038 / \mathrm{nn} .4463$

Mentis, G. Z., Gravell, M., Hamilton, R., Shneider, N. A., O'Donovan, M. J., and Schubert, M. (2006). Transduction of motor neurons and muscle fibers by intramuscular injection of HIV-1-based vectors pseudotyped with select rabies virus glycoproteins. J. Neurosci. Methods 157, 208-217. doi: 10.1016/j. jneumeth.2006.04.011

Miyamichi, K., Amat, F., Moussavi, F., Wang, C., Wickersham, I., Wall, N. R., et al. (2011). Cortical representations of olfactory input by trans-synaptic tracing. Nature 472, 191-196. doi: 10.1038/nature09714

Obeso, J. A., Rodriguez-Oroz, M. C., Goetz, C. G., Marin, C., Kordower, J. H., Rodriguez, M., et al. (2010). Missing pieces in the Parkinson's disease puzzle. Nat. Med. 16, 653-661. doi: 10.1038/nm.2165

Oh, S. M., Chang, M. Y., Song, J. J., Rhee, Y. H., Joe, E. H., Lee, H. S., et al. (2015). Combined Nurr1 and Foxa2 roles in the therapy of Parkinson's disease. EMBO Mol. Med. 7, 510-525. doi: 10.15252/emmm.201404610

Ohara, S., Inoue, K., Witter, M. P., and Iijima, T. (2009). Untangling neural networks with dual retrograde transsynaptic viral infection. Front. Neurosci. 3, 344-349. doi: 10.3389/neuro.01.032.2009

Oyibo, H. K., Znamenskiy, P., Oviedo, H. V., Enquist, L. W., and Zador, A. M. (2014). Long-term Cre-mediated retrograde tagging of neurons using a novel recombinant pseudorabies virus. Front. Neuroanat. 8:86. doi: 10.3389/fnana. 2014.00086

Perrelet, D., Ferri, A., Mackenzie, A. E., Smith, G. M., Korneluk, R. G., Liston, P., et al. (2000). IAP family proteins delay motoneuron cell death in vivo. Eur. J. Neurosci. 12, 2059-2067. doi: 10.1046/j.1460-9568.2000.00098.x

Pomeranz, L. E., Reynolds, A. E., and Hengartner, C. J. (2005). Molecular biology of pseudorabies virus: impact on neurovirology and veterinary medicine. Microbiol. Mol. Biol. Rev. 69, 462-500. doi: 10.1128/mmbr.69.3.462500.2005

Redmond, D. E. Jr., McEntire, C. R., Kingsbery, J. P., Leranth, C., Elsworth, J. D., Bjugstad, K. B., et al. (2013). Comparison of fetal mesencephalic grafts, AAV-delivered GDNF, and both combined in an MPTP-induced nonhuman primate Parkinson's model. Mol. Ther. 21, 2160-2168. doi: 10.1038/mt.20 13.180

Ren, X., Zhang, T., Gong, X., Hu, G., Ding, W., and Wang, X. (2013). AAV2mediated striatum delivery of human CDNF prevents the deterioration of midbrain dopamine neurons in a 6-hydroxydopamine induced parkinsonian rat model. Exp. Neurol. 248, 148-156. doi: 10.1016/j.expneurol.2013.06.002

Salegio, E. A., Samaranch, L., Kells, A. P., Mittermeyer, G., San Sebastian, W., Zhou, S., et al. (2013). Axonal transport of adeno-associated viral vectors is serotype-dependent. Gene Ther. 20, 348-352. doi: 10.1038/gt.2012.27
San Sebastian, W., Samaranch, L., Heller, G., Kells, A. P., Bringas, J., Pivirotto, P., et al. (2013). Adeno-associated virus type 6 is retrogradely transported in the non-human primate brain. Gene Ther. 20, 1178-1183. doi: 10.1038/gt.2013.48

Schwarz, L. A., Miyamichi, K., Gao, X. J., Beier, K. T., Weissbourd, B., DeLoach, K. E., et al. (2015). Viral-genetic tracing of the input-output organization of a central noradrenaline circuit. Nature 524, 88-92. doi: $10.1038 /$ nature 14600

Senn, V., Wolff, S. B., Herry, C., Grenier, F., Ehrlich, I., Gründemann, J., et al. (2014). Long-range connectivity defines behavioral specificity of amygdala neurons. Neuron 81, 428-437. doi: 10.1016/j.neuron.2013.11.006

Tanabe, S., Inoue, K., Tsuge, H., Uezono, S., Nagaya, K., Fijiwara, M., et al. (2017). The use of an optimized chimeric envelope glycoprotein enhances the efficiency of retrograde gene transfer of a pseudotyped lentiviral vector in the primate brain. Neurosci. Res. 120, 45-52. doi: 10.1016/j.neures.2017. 02.007

Tervo, D. G., Hwang, B. Y., Viswanathan, S., Gaj, T., Lavzin, M., Ritola, K. D., et al. (2016). A designer AAV variant permits efficient retrograde access to projection neurons. Neuron 92, 372-382. doi: 10.1016/j.neuron.2016.09.021

Themis, M., Waddington, S. N., Schmidt, M., von Kalle, C., Wang, Y., AlAllaf, F., et al. (2005). Oncogenesis following delivery of a nonprimate lentiviral gene therapy vector to fetal and neonatal mice. Mol. Ther. 12, 763-771. doi: 10.1016/j.ymthe.2005.07.358

Thomas, C. E., Ehrhardt, A., and Kay, M. A. (2003). Progress and problems with the use of viral vectors for gene therapy. Nat. Rev. Genet. 4, 346-358. doi: $10.1038 / \operatorname{nrg} 1066$

Tohyama, T., Kinoshita, M., Kobayashi, K., Isa, K., Watanabe, D., Kobayashi, K., et al. (2017). Contribution of propriospinal neurons to recovery of hand dexterity after corticospinal tract lesions in monkeys. Proc. Natl. Acad. Sci. U S A 114, 604-609. doi: 10.1073/pnas.1610787114

Ugolini, G. (2008). Use of rabies virus as a transneuronal tracer of neuronal connections: implications for the understanding of rabies pathogenesis. Dev. Biol. 131, 493-506.

Wakaizumi, K., Kondo, T., Hamada, Y., Narita, M., Kawabe, R., Narita, H., et al. (2016). Involvement of mesolimbic dopaminergic network in neuropathic pain relief by treadmill exercise: a study for specific neural control with Gi-DREADD in mice. Mol. Pain 12:1744806916681567. doi: $10.1177 / 1744806916681567$

Wickersham, I. R., Lyon, D. C., Barnard, R. J., Mori, T., Finke, S., Conzelmann, K. K., et al. (2007). Monosynaptic restriction of transsynaptic tracing from single, genetically targeted neurons. Neuron 53, 639-647. doi: 10.1016/j.neuron.2007.01.033

Wong, L. F., Goodhead, L., Prat, C., Mitrophanous, K. A., Kingsman, S. M., and Mazarakis, N. D. (2006). Lentivirus-mediated gene transfer to the central nervous system: therapeutic and research applications. Hum. Gene Ther. 17, 1-9. doi: 10.1089/hum.2006.17.1

Zemanick, M. C., Strick, P. L., and Dix, R. D. (1991). Direction of transneuronal transport of herpes simplex virus 1 in the primate motor system is straindependent. Proc. Natl. Acad. Sci. U S A 88, 8048-8051. doi: 10.1073/pnas.88. 18.8048

Zheng, J. S., Tang, L. L., Zheng, S. S., Zhan, R. Y., Zhou, Y. Q., Goudreau, J., et al. (2005). Delayed gene therapy of glial cell line-derived neurotrophic factor is efficacious in a rat model of Parkinson's disease. Mol. Brain Res. 134, 155-161. doi: 10.1016/j.molbrainres.2004.06.029

Conflict of Interest Statement: The authors declare that the research was conducted in the absence of any commercial or financial relationships that could be construed as a potential conflict of interest.

Copyright $\odot 2017$ Kobayashi, Inoue, Tanabe, Kato, Takada and Kobayashi. This is an open-access article distributed under the terms of the Creative Commons Attribution License (CC BY). The use, distribution or reproduction in other forums is permitted, provided the original author(s) or licensor are credited and that the original publication in this journal is cited, in accordance with accepted academic practice. No use, distribution or reproduction is permitted which does not comply with these terms. 